tween solid particles. It proved to be a significant contribution.

The results of these calculations led to the Arrhenius plot of Figure 1, where a single straight line reasonably correlates Fulton's data. The slope of this line gives an activation energy of $11.4 \mathrm{kcal}$./g.-mole. According to the present interpretation, no shift in the reaction mechanism need be invoked.

In Figure 2 some data taken by the author are reported. They show a higher frequency factor than that obtained by Fulton, although the data were taken with the use of a catalyst containing approximately the same nickel percentage as in Fulton's work. This apparently higher frequency factor may be due to an improved purification system used in the present experimental work. The complete procedure outlined above as well as a description of the equipment are reported in reference 6 .

\section{ACKNOWLEDGMENT}

This work was done while the author was doing research for his M.Ch.E. degree at the University of Kansas.

\section{LITERATURE CITED}

1. Fulton, J. W., Ph.D. thesis, Oklahoma Univ., Norman (1964).

2. Eichhorn, J., and R. R. White, Chem. Eng. Prog. Symp. Ser. No. 4, 48, 11 (1952).

3. Bar-Ilan, Moshe, and M. W. Resnick, Ind. Eng. Chem., 49, 313 (1957)

4. Williamson, J. E., K. E. Bazaire, and C. J. Geankoplis, Ind. Eng. Chem. Fundamentals, 2, 126 (1963).

5. Weisz, P. B., and J. S. Hicks, Chem. Eng. Sci., 17, 265 (1962).

6. Gioia, Francesco, Chim. Ind., 48, 237 (1966).

7. Fulton, J. W., and O. K. Crosser, A.I.Ch.E. J., 11, 513 (1965).

\title{
Cocurrent Flows of Two Immiscible Viscous Fluids Over a Flat Plate
}

\section{HSU-CHIEH YEH and WEN-JEI YANG \\ University of Michigan, Ann Arbor, Michigan}

Consideration is given to the laminar boundary-layer How over a permeable flat surface through which an immiscible foreign fluid is released into the boundary layer. Thus, there is formed a buffer between the surface and the main stream, that is, there coexist two boundary layers. The drag reduction characteristics of the two-phase boundary layer were investigated by Sparrow et al. (1) through the use of the series expansion method. The present analysis extends the study to include its heat transfer characteristics; other literature pertinent to the work includes references 2,3 , and 4 .

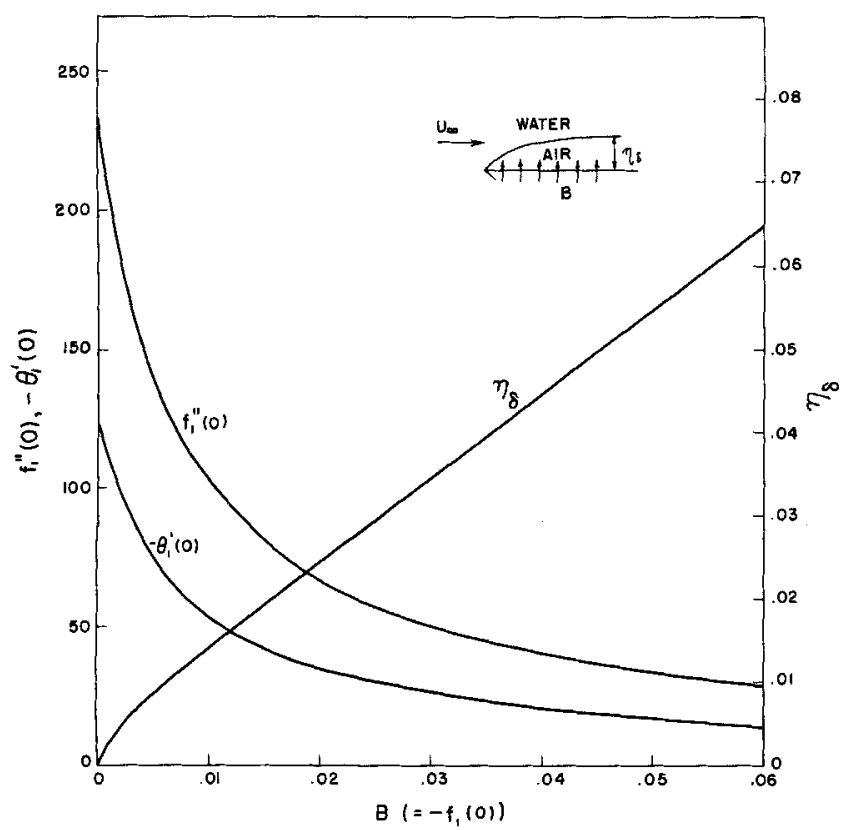

Fig. 1. Effects of the releose rate of air into water stream on heat transfer and skin friction.
The application of the conservation principle of energy produces two laminar boundary-layer equations, one for the main stream fluid and the other for the foreign fluid. Each equation is reduced to an ordinary differential equation by similarity transformation

$$
\theta^{\prime \prime}+N_{P r} f \theta^{\prime}=0
$$

for both boundary layers. The matching and boundary conditions are

Plate surface:

Interface:

$$
\theta_{1}(0)=1
$$

$$
\begin{aligned}
& \theta_{1}\left(\eta_{\delta}\right)=\theta_{2}(0) \\
& \theta_{1}^{\prime}\left(\eta_{\delta}\right)=\left(k_{2} / k_{1}\right)\left(\nu_{1} / \nu_{2}\right)^{1 / 2} \theta_{2}^{\prime}(0)
\end{aligned}
$$

Free stream:

$$
\theta_{2}(\infty)=0
$$

The Nusselt number $N_{N u}$ at the plate surface may be expressed in dimensionless form as

$$
N_{N u} / N_{R e^{1 / 2}}=-1 / 2 \theta_{1}^{\prime}(0)
$$

Consideration was given to two cases: the release of water into air stream and vice versa. Fluid properties corresponding to $100^{\circ} \mathrm{F}$. were used. With the solutions for $f_{1}$ and $f_{2}$ obtained in reference 1 , as input data, Equations (1) for both inner and outer boundary layers were numerically integrated for $\theta_{1}$ and $\theta_{2}$ by the Runge-Kutta method with an IBM 7090 digital computer. The results are illustrated in Figures 1 and 2 for the release of air into water stream corresponding to $\left[(\rho \mu)_{2} /(\rho \mu)_{1}\right]^{1 / 2}=$ 177 and $\left(k_{2} / k_{1}\right)\left(\nu_{1} / \nu_{2}\right)^{1 / 2}=117$ and that of water into air stream corresponding to $\left(\rho_{2} \mu_{2} / \rho_{1} \mu_{1}\right)^{1 / 2}=0.00565$ and $\left(k_{2} / k_{1}\right)\left(\nu_{1} / \nu_{2}\right)^{1 / 2}=0.00853$, respectively. $f_{1}^{\prime \prime}(0)$ represents the skin friction grouping $4 N_{R e} e^{1 / 2} / \rho_{1} U_{\infty}{ }^{2}$ as obtained in reference 1 . The figures show that the release of foreign fluids to form a buffer between the main stream and the wall affects appreciably the transport phenomenon, caus- 


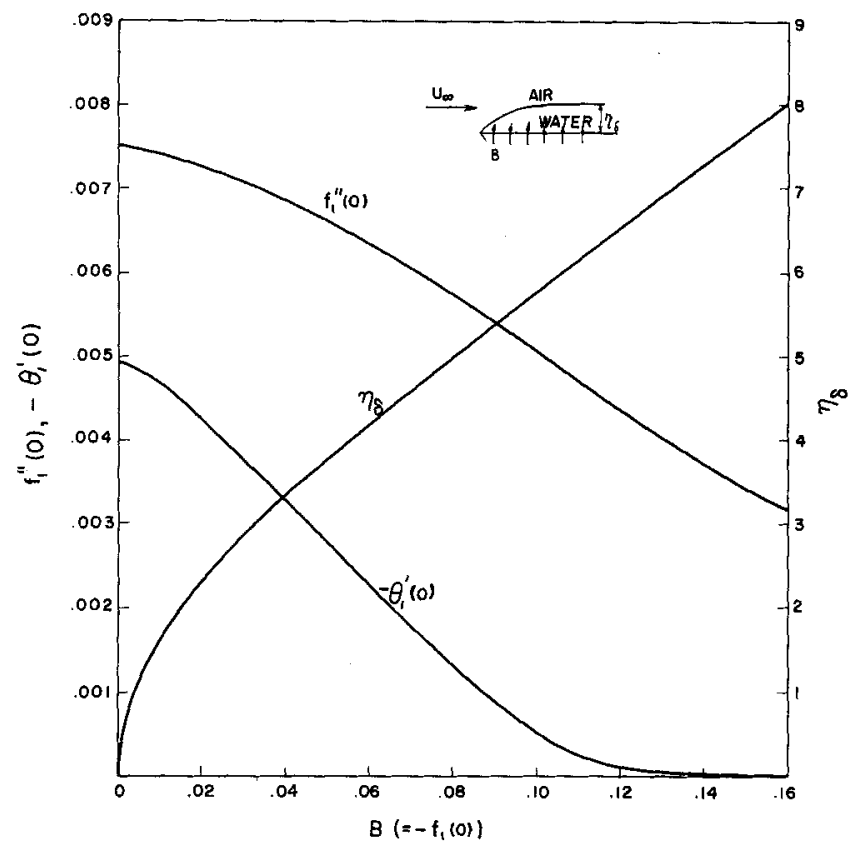

Fig. 2. Effects of the release rate of water into oir stream on heat transfer and skin friction.

ing a decrease in both heat transfer and skin friction. The effect will be most severe for the release of air into water stream, for which $\left(\rho_{2} \mu_{2} / \rho_{1} \mu_{1}\right)^{1 / 2}$ can attain very high values. Therefore the cocurrent flow may be applied as a means to reduce the drag experienced by bodies moving through liquids and transpiration cooling of heated surface.

\section{NOTATION}

$B \quad=$ blowing parameter

$f=$ dimensionless stream function defined as $\psi /\left(U_{\omega} \nu x\right)^{1 / 2}$ $k \quad=$ fluid thermal conductivity

$N_{N u}=$ Nusselt number

$N_{P r}=$ Prandtl number

$N_{R e}=$ Reynolds number

$T=$ fluid temperature inside the boundary layer

$T_{w}=$ wall temperature

$T_{\infty}=$ free-stream temperature

$U_{\infty}=$ free-stream velocity

$V_{1}=$ blowing velocity at surface, $\frac{B}{2}\left(U_{\omega} \nu_{1} / x\right)^{1 / 2}$

$x \quad=$ coordinate along plate

$y=$ coordinate normal to plate

\section{Greek Letters}

$\delta \quad=$ thickness of inner boundary layer

$\eta \quad=$ similarity variable, $\eta_{1}=1 / 2 y\left(U_{\alpha} / \nu_{1} x\right)^{1 / 2}, \eta_{2}=$ $\frac{y-\delta}{2}\left(U_{\odot} / \nu_{2} x\right)^{1 / 2}$

$=1 / 2 \delta\left(U_{\infty} / \nu_{1} x\right)^{1 / 2}$

$=\left(T-T_{\infty}\right) /\left(T_{w}-T_{\infty}\right)$

$=$ absolute viscosity

$=$ kinetic viscosity

$=$ fluid density

$=$ wall shear stress

$=$ stream function

\section{Subscripts}

1 = inner boundary layer (foreign fluid)

2 = outer boundary layer (main stream)

\section{LITERATURE CITED}

1. Sparrow, E. M., V. K. Johnson, and E. R. G. Eckert, J. Appl. Mech., Ser. E, 29, 408-411 (1962).

2. Koh, J. C., Intern. J. Heat Mass Transfer, 5, 941-954 (1962).

3. Cess, R. D., and E. M. Sparrow, J. Heat Transfer, C83, 370-376 (1961).

4. Ibid., 377-378.

\section{A Generalized Equation for Solids Distribution in the}

\section{Semifluidized MT Reactor}

\section{K. BABU RAO and L. K. DORAISWAMY}

National Chemical Laboratory, Poona, India

$$
\left(\frac{h-h_{s}}{h-h_{p}}\right) \text { vs. }\left(\frac{G_{s}-G_{m f}}{G_{t}-G_{m f}}\right)
$$

A new type of fluid-solid contact operation, called semi-
fuidization, was proposed by Fan et al. (11), and a few further studies on this technique have also been reported $(6,10)$. Babu Rao et al. (3) have utilized the principle of semifluidization for proposing a new type of combined MT reactor system. The MT combination denotes a fully mixed reactor followed by a tubular reactor. The characteristic features of MT reactors have been discussed at length $(1,9,14)$, and the advantages of using the semifluidized bed for an MT combination have been outlined (3). However, the existing information on the mechanics of semifluidization (which is essential in designing an MT semifluidized bed reactor) is fragmentary, and the correlations of Fan and collaborators provide significant guidelines for further work in this area.

The dimensionless relationship proposed $(6,10)$ has been derived for a semifluidized bed without the complicating features introduced by the use of a tubular bundle at the top for promoting piston flow. In an MT semifluidized bed reactor the height of the tubular portion will vary, depending on the number of tubes, since the total quantity of solids forming the packed bed below the restraining plate would be the same regardless of the number of tubes at a given semifluidization velocity. Equation (1) cannot therefore be applied to this reactor. Another feature of Equation (1) which needs closer analysis is the assumption that the height of the packed section when all the solids have been conveyed to the 